\title{
Optics history as effective instrument for education in optics and photonics
}

\author{
S. K. Stafeef, M. Tomilin
}

S. K. Stafeef, M. G. Tomilin, "Optics history as effective instrument for education in optics and photonics," Proc. SPIE 9666, 11th Education and Training in Optics and Photonics Conference, 966607 (5 June 2009); doi: 10.1117/12.2207938

SDIE Event: Eleventh International Topical Meeting on Education and Training in Optics and Photonics, 2009, St. Asaph, United Kingdom 


\title{
Optics history as effective instrument for education in optics and photonics
}

\author{
S.K. Stafeef and M.G. Tomilin \\ St.-Petersburg University of Information Technologies, Mechanics and Optics, St.- \\ Petersburg, 197101, Kronverksky Pr. 49, Russia
}

\begin{abstract}
The education problem in optics and photonics is to draw young generation on the side of light, optical science and technology. The main goal is to prove the slogan that "physics is a small part of optics": during the thousand years optics formulated the clear worldview for humanity. In fact optics is itself presents multidisciplinary collection of independent scientific arias from one hand and was a generator of new fields of knowledge from the other hand. Optics and photonics are the regions where the fundamental problems of our reality have to be solved. The mentioned functions belonged to optics during the period of civilizations development. This is a basic idea of books serial by S. Stafeev and M. Tomilin "Five Millennium of Optics" including 3 volumes. The first volume devoted to optics prehistory was edit in 2006 in Russian. Its main chapters devoted to relations between Sun and Life, the beginnings of human intelligence, megalithic viewfinders, gnomons and ancient temples orientation, archaic optical materials and elements. It also consist the optical riddles of that period. The volume II is devoted to Greek and Roman antiquity and is in the process of publishing. It consist the chapters on the beginning of optics, mathematical fundaments and applied optics evolution. Volume III would be devoted to Medieval and Renaissance optics history. The materials are used at our university in a course "The Modern Natural Science Conceptions" for students and graduate students. In our paper the possibilities of optics history as effective instrument for education in optics and photonics are discussed.
\end{abstract}

Keywords: optics prehistory; medieval and renaissance optics; ancient images, megalithic viewfinders, gnomons and temples orientation; optical theory, materials and elements; eye and vision.

\section{INTRODUCTION}

Optics and photonics have exciting history closely tied with modern science. For receiving the harmonious education in this field it is necessary to trace the development of optics from early beginning up to current state. Such panorama of optics development arise deep interest of pupils to the subject of investigation and give fundamental knowledge. Sun light as main source of energy and basis of life was the most important object of investigation during the whole period of civilization evolution. Vision as the main source of information about the surrounded world determined the evolution of human intellect. The direct sky objects observation during thousand years helped to predict nature cycle changes and to fix man in time and space. Control of Sun, Moon and planets trajectories gave the calendar to many nations. Many megalithic facilities and observatories were built for this and religious purposes. Viewfinder as one of the first optical instrument was created as the result of ancient visual observations. Other ancient optical elements such as mirrors, lenses and magic spheres were the result of handicraft activity in metallurgy and jeweler's art. Transparent crystals processing and glass-making create the basis of ancient optical materials.

During the prehistoric period optics had a syncretic stage with ancient philosophy and religion and had a magic context. Greek and Roman antiquity was characterized by serious interest to nature of light and mechanisms of vision. The famous Greek thinkers founded the basis of geometric optics, catoptrics, dioptrics and meteors. The contribution of outstanding scientists Euclid, Archimedes and Ptolemy to optics produced a strong influence on following ages. The main achievement of middle ages was the invention of glasses, while 
the main achievement of Renaissance was the development of perspective theory, demonstrating the optical knowledge penetration into fine arts technology.

In our paper the general context with selected illustrations of two our books is presented to give the common impression of collected information on civilizations history seen by optician eyes.

\section{FIVE MILLENIUM OF OPTICS: PREHISTORY}

Introduction

Chapter 1. Sun and Life

1.1. Sun messenger

1.2. Beginnings of life

1.3. Light, eye and brain

1.4. Sun-earth interconnections

Chapter 2. The cradle of intellect

2.2. Horr eye (fig.2)

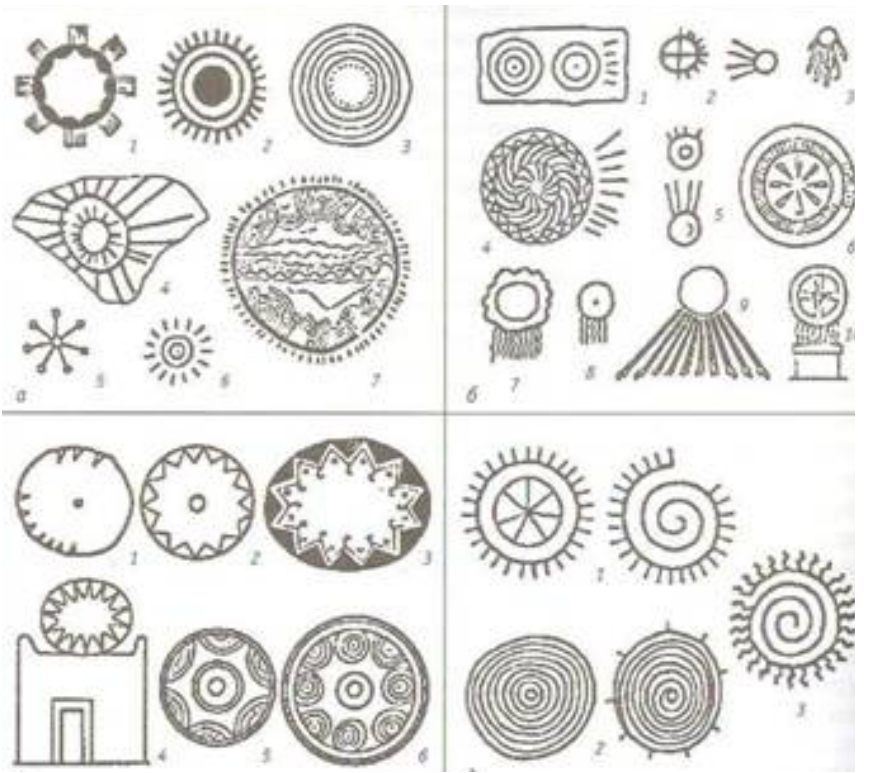

Fig.1. Sun symbols of different nations and times
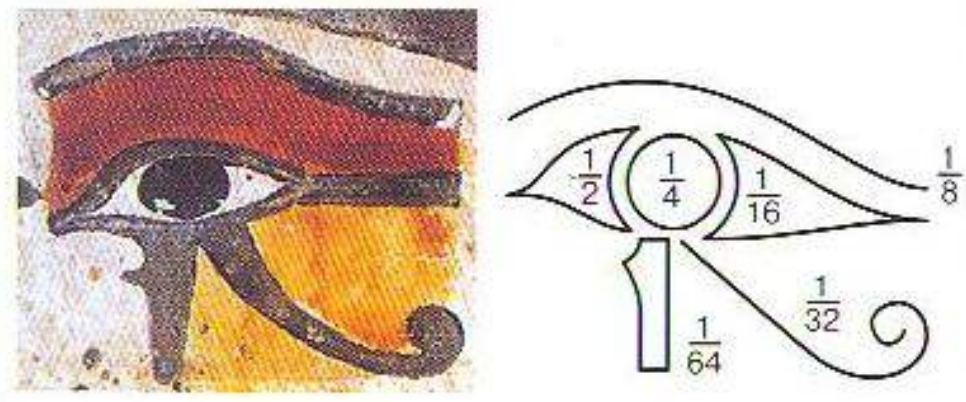

Fig.2. Horr eye and its interpretation as fractions

2.3. Images and letters 


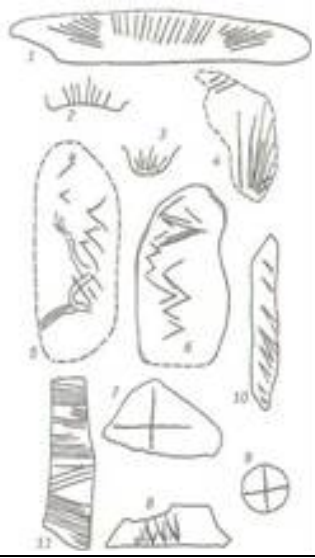

Fig.3. Calendar marks on bones from pal eolith.

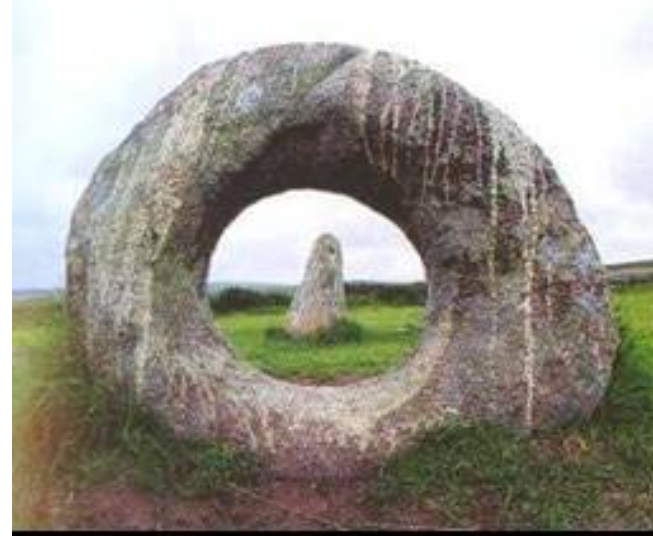

Fig.4. Stone menhir with seculated viewfinder aperture

Chapter 3. Megalithic viewfinders

3.1. Megalithic civilization and stone viewfinders (fig.4)

3.2. Linear backing. Menhirs, leis and stone ranges

3.3. Viewfinders with seculated aperture. Dolmen and dromoses

3.4. Cromlechs and horizon observatories

Chapter 4. Gnomons and ancient temples orientation
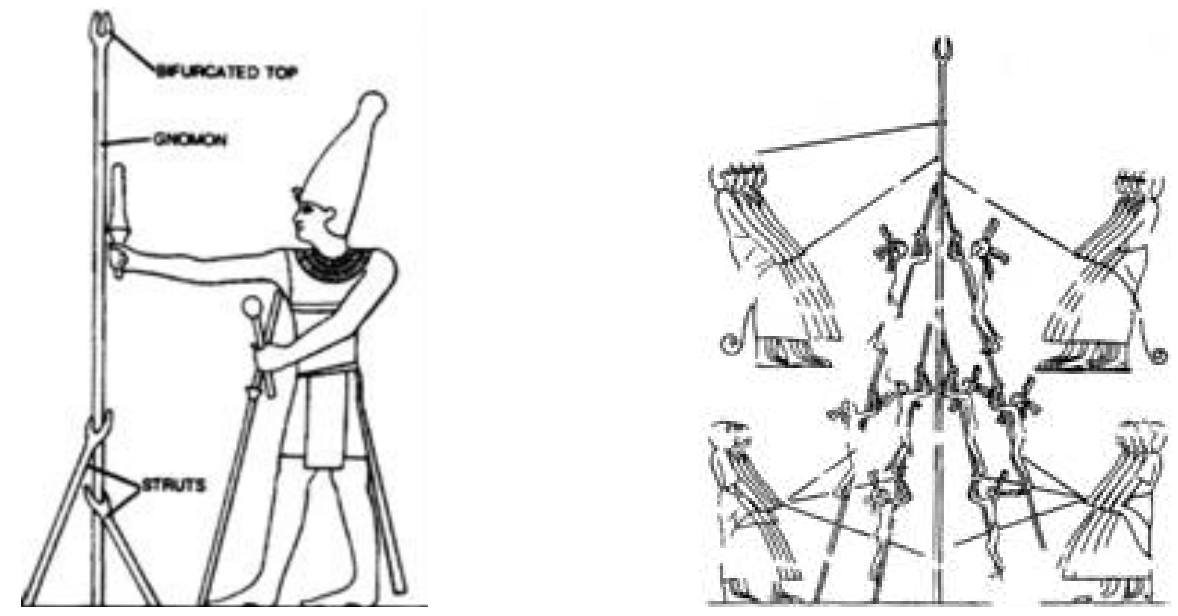

Fig.5. Gnomons in ancient Egypt

4.2. Sacred symbols of ancient viewfinders

4.3. Temple complexes orientation in Europe and Asia

Chapter 5. Archaic optics: materials and elements

5.1. Bronze mirrors (fig.6)

5.2. Magic mirrors of China and Japan (fig.7) 


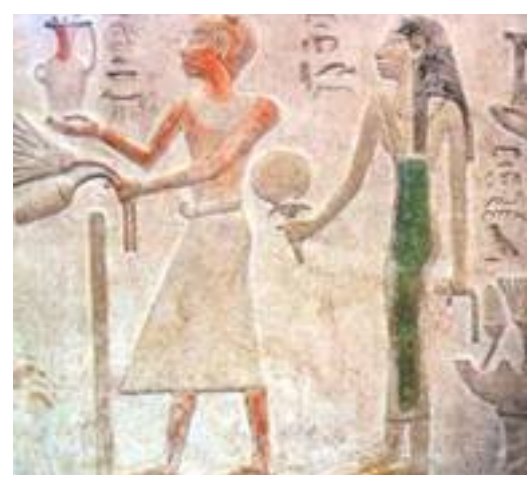

Fig.6. Ancient Egyptian mirror

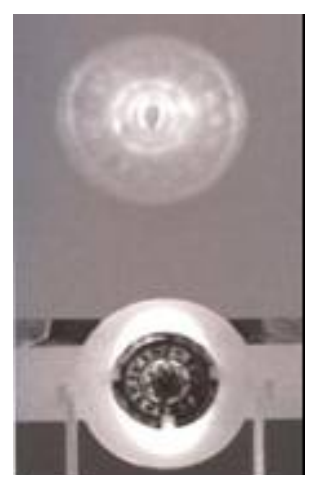

Fig.7. China magic mirror

5.3. Natural crystals and its processing
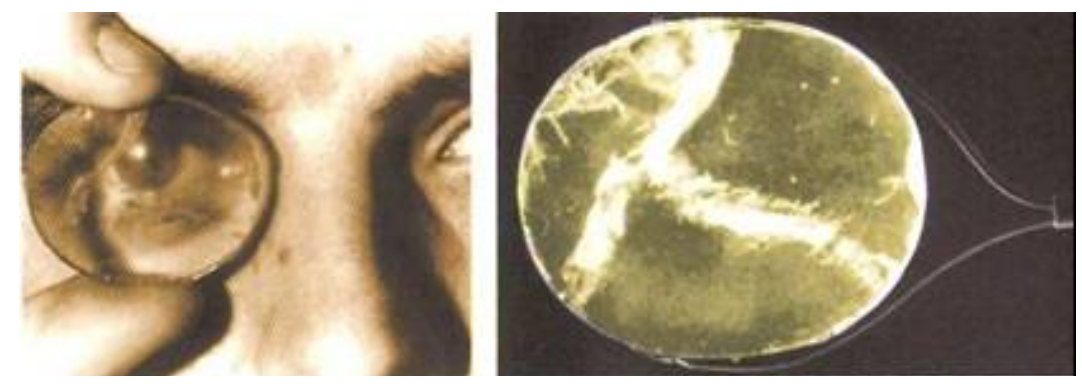

Fig.8. Ancient crystalline lens from Ninevia, VIII BC.

\subsection{First glass}

Application. Ancient optical mysteries

1. Mystery of megaliths

2. Pyramids, Orion constellation and Zodiac cycles

3. Myths of ancient Egypt and Arcaim

4. Viewfinders for skies

289

5. Ancient telescope (fig.9)
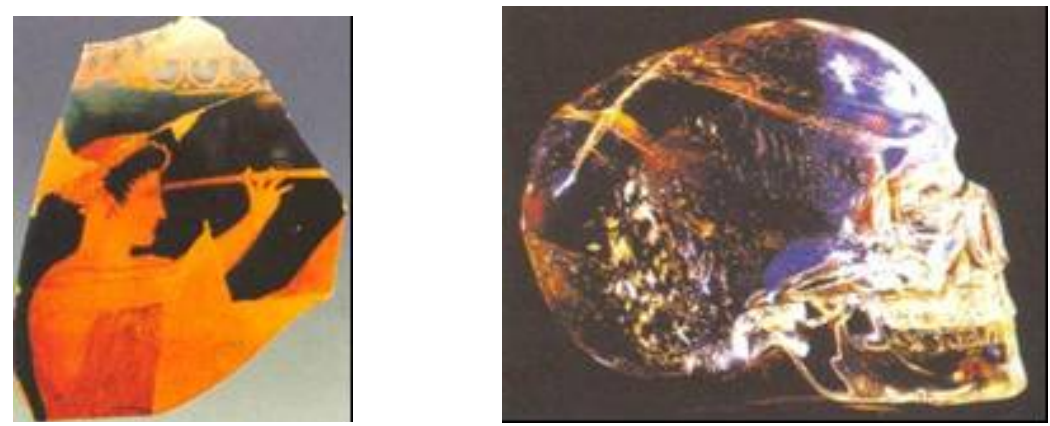

Fig.9. Ancient telescope? Fig.10. Quartz scull illustrate HT handling

6. Quartz sculls (fig 10).

Conclusion

Literature (295 pos.) 


\section{FIVE MILLENIUM OF OPTICS: ANTIQUITY}

Introduction

Part I. Principles of antique optics

Chapter 1. Antique mythology and light metaphysics

1.1. Light and vision in mythology (fig1)

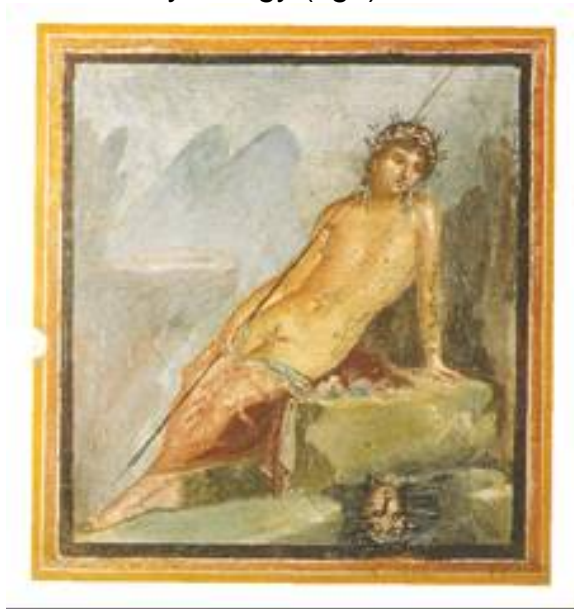

Fig.1. Narcissus and his reflex.

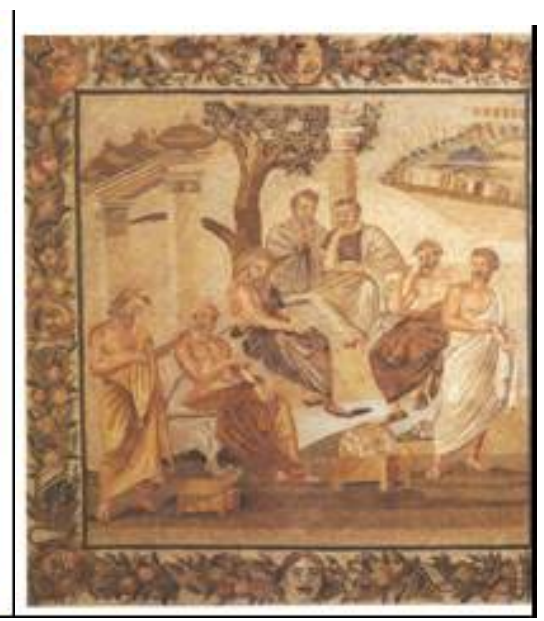

Fig.2. Plato Academy.

1.2. Metaphysics and natural philosophy of light

1.3. Color symbolism and antique chromatism

Chapter 2. Main stages of scientific knowledge evolution

2.1. Classification of scientific disciplines

2.2. Main stages of antique science (fig.2)

2.3. Optics among antique disciplines

Chapter 3. Physical theories of visual perception

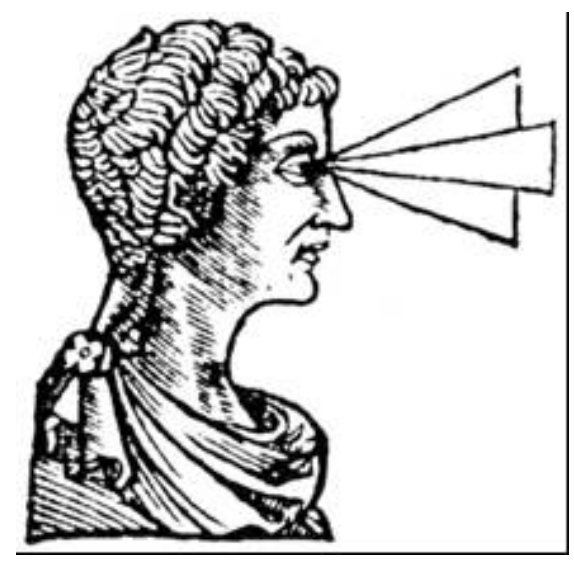

Fig.3.Ocular beams 


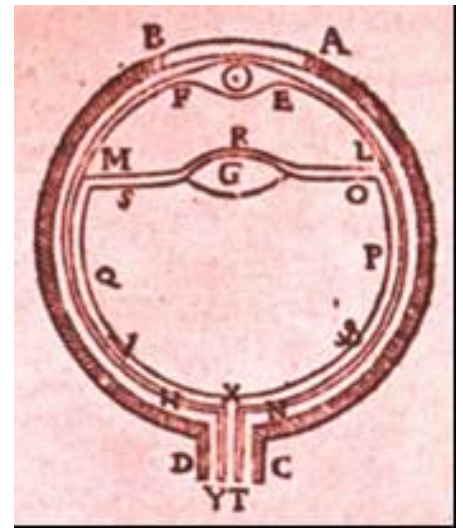

Fig.4. Galen's model of eye

4.2. Vision psychology. Optical illusions

Part II. Mathematical principles of optics

Chapter 5. Studies of direct vision

5.1. Optics of vision

5.2. Direct vision in Euclid "Optics"

201

5.3. Direct vision in Archimedes and Hero "Catoptrics"

206

5.4. .Direct vision in Ptolemy "Optics"

$\begin{array}{lr}\text { Chapter 6. Catoptrics } & 220\end{array}$

$\begin{array}{lr}\text { 6.1. Euclid's catoptrics } & 222\end{array}$

6.2 Archimedes' and Hero's catoptrics $\quad 227$

6.3. Catoptrics theorems in Ptolemy "Optics" 230

6.4. Multiple mirror systems and burning mirrors $r 241$

6.5 Archimedes' burning mirrors (fig.5)

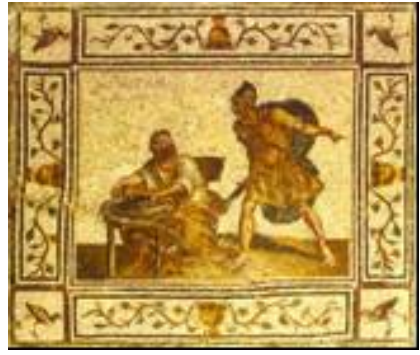

Fig.5. Antique mosaic with the scene of Archimedes death 
7.1. Ptolemy's theoretical analysis of refraction $\quad 260$

7.2. Ptolemy experiments with light refraction 262

$\begin{array}{lr}7.3 \text { Atmosphere refraction } & 268\end{array}$

$\begin{array}{ll}\text { 7.4. Localization of refractive images and their distortion } & 270\end{array}$

Chapter 8. Meteors $\quad 276$

8.1. Aristotle's Meteorologica $\quad 279$

8.2. Theory of humid meteors $\quad 283$

8.3. Theory of circular meteors (fig.6) 286

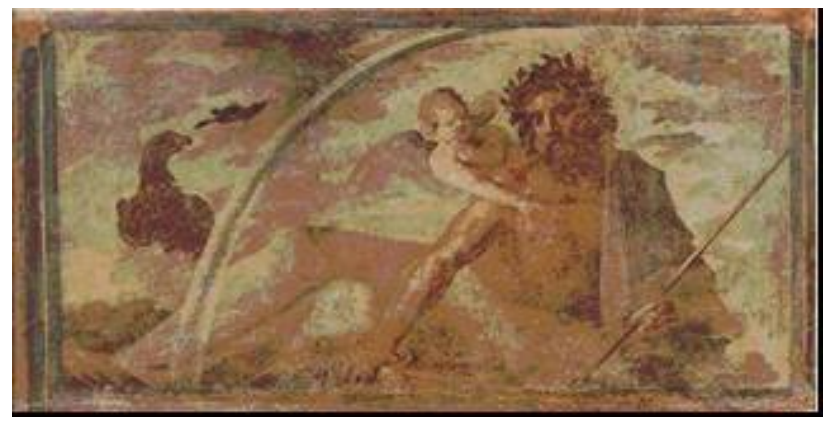

Fig.6. Antique mosaic with rainbow

8.4 Theory of visual rays for study meteors

Part III. The beginning of applied optics 297

Chapter 9. Optical materials, elements and technologies 298

9.1. Bronze and mirrors (fig.7)

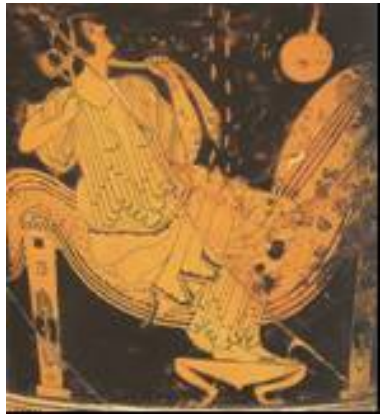

Fig.7. Fragment of vase decoration

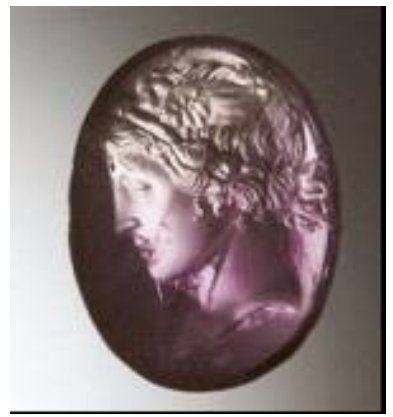

Fig.8. Intalia

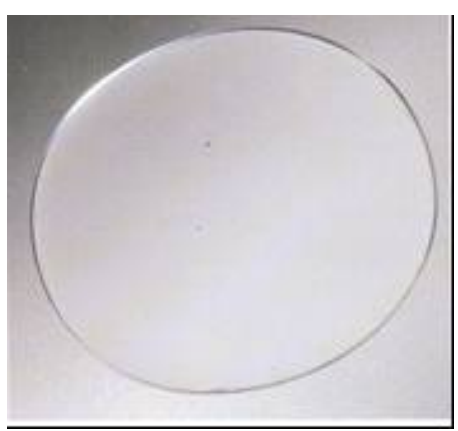

Fig.9. Antique crystal lens

9.2 Optical crystals and jewelry produces (Fig.8)

9.3. Crystal lenses (fig.9)

9.4. Schliemann lenses and Nero monocle

9.5. Crystal spheres. Antique telescope

9.6. Glasses and decoration produces 
10.2 Evolution of viewfinders

10.3. Lamps

10.4. Lighthouses and light telegraph

Chapter 11. Optics and arts 382

11.1. Paintings (fig.10)

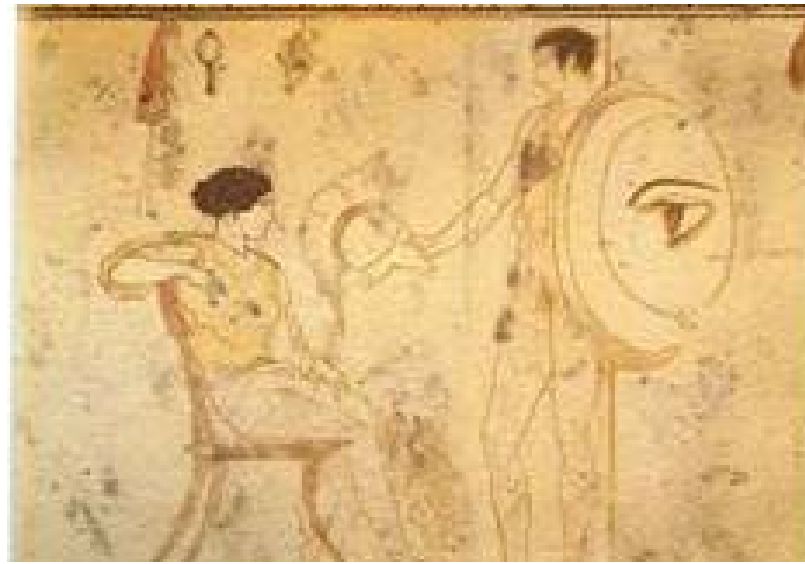

Fig.10 Fragment of antique vase decoration

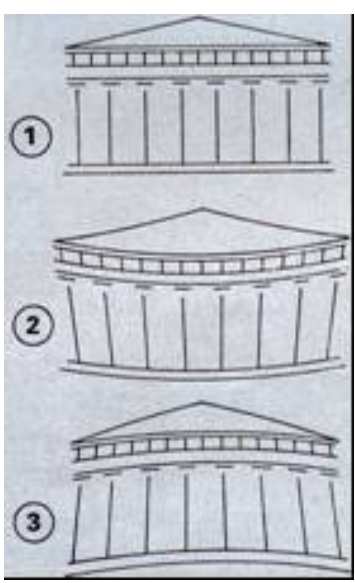

Fig.11. Optics in architecture

\subsection{Scenography}

391

11.3 Sculpture

396

11.4 Architecture (fig.11)

398

11.5. Theatre

Conclusion

Applications

Archit and optics

Lucretsy and vision

Theofrast

We hope that brief review will give the common impression about the context of our books. The conference on education and training in optics and photonics at Technium OpTIC at St. Asaph is a good opportunity to discuss possible profit of translating two volumes of "FIVE MILLENIUM OF OPTICS" into English. The authors use the study of optics history for education in optics and photonics themselves and recommend other specialist to follow their practice. 